\title{
Development of a YAMUGAG-20 Wireless Exploder for Safe Disposal of Military and Civil Explosives
}

\author{
A. M. Na'inna, M. B. Yakubu, A. Mohammed, P. A. Uzuazor, A. Y. Abdullahi, U. H. Goje, \\ A. Audu, and I. N. Gana
}

\begin{abstract}
YAMUGAG-20 Exploder is a Radio Frequency (RF)-based wireless exploder system designed and constructed specially for the Nigerian Air Force (NAF) to overcome the challenges associated with the existing wired exploders used for the disposal of unserviceable ordnances. The Exploder system has three main parts namely, the master transmitter unit, the master receiver/slave transmitter unit, and the slave receiver unit. Each of these units is made up of transceiver module, microcomputer and power source. The microcomputers were programmed using $\mathrm{C}$ and $\mathrm{C}++$ programming language of the Integrated Development Environment (IDE) software. The exploder is portable and easy to operate. For a typical demolition exercise, the operation of the exploder is such that signals are relayed from the master transmitter unit to the master receiver/slave transmitter unit onto the slave receiver unit to initiate an electric detonator leading to the detonation of the unserviceable ordnances. Functionality, range, power consumption, and system reliability tests were conducted on the exploder to establish its performance and efficiency. The results obtained from the tests indicated that the exploder transmitting at a frequency of $2.4 \mathrm{GHz}$ performed satisfactorily up to a range of 1000 meters. Therefore, the exploder has the potential of not only meeting the demolition demands of the NAF but can also be applied for other nonmilitary purposes like mining and related activities.
\end{abstract}

Index Terms - Exploder, Radio-Frequency, Demolition, Blasting.

\section{INTRODUCTION}

In the military, unserviceable ordnances (USO) are those types of ordnances that are usually beyond repairs and their continued storage pose serious threat to lives and properties, hence the need for their safe demolition. In the Nigerian Air Force (NAF), demolition of USO is usually achieved by detonating the unserviceable ordnances at a demolition site through the use of wired exploders. The major challenge encountered with these wired exploders over time has been the issue of continuity associated with the wire [1]. The risk associated with fixing this challenge having primed the USO for demolition can be unprecedented considering the fact that it may cost lives.

To overcome this challenge, the idea of adopting wireless transmission was suggested. Wireless transmission system is

Published on February 3, 2021

A. M. Na'inna, Nigerian Air Force, Nigeria.

(e-mail: amnainna@gmail.com).

M. B. Yakubu, Nigerian Air Force, Nigeria.

(e-mail: bashaish12@ gmail.com)

A. Mohammed, Nigerian Air Force, Nigeria.

(e-mail: mohammed.abubakar84@yahoo.com)

P. A. Uzuazor, Nigerian Air Force, Nigeria.

(e-mail: uzuazor.precious ${ }^{\circledR}$ gmail.com). the use of Radio Frequency (RF), which is one of the electromagnetic wave frequencies from around $3 \mathrm{KHz}$ to $300 \mathrm{GHz}$, for signal transmission in wireless communication as opposed to communication via electric wires [2]. Wireless exploders present opportunities for demolition exercises without the need for physical wire connections between the exploder and the unserviceable stores [3].

The normal method of firing an electric detonator in a typical demolition or blasting exercise is to apply electric energy from a power source such as a blasting machine (exploder) to the open ends of the detonator wires. This electrical energy flows through the wires to the detonator and causes the resistance wire inside the detonator to heat the primary explosives to the burning (explosion) temperature [4]. Therefore, the role of the exploder is to provide sufficient current over a distance to initiate one or more detonators or other electrical initiators [5].

\section{RELATED WORKS}

There is a collection of related works done by scientists and researchers on wireless exploders also known as wireless blasting machines. A review of some of these works are presented in succeeding paragraphs.

Dirk et al. [3] designed and developed a wireless detonator assembly with a corresponding blasting apparatus. The wireless detonator assembly comprises a charge storage device that is capable of storing charge for discharge into a firing circuit upon receipt of appropriate wireless command signal from an associated blasting machine. The challenge associated with the detonator assembly is that the charge storage device becomes uncharged for a specific period of time upon receipt of the appropriate command. Additionally, the charge storage device discharges with little or no effect upon the firing circuit, and the wireless detonator assembly adopts a safe mode [3]

In a related work, a method of communication with a detonator device using RFID (Radio-Frequency Identification) technology to read data from the device, and to transmit information and commands to the device was carried out by Koekemer et al. [6]. In one particular application, communication with the tag mounted inside

A. Y. Abdullahi, Nigerian Air Force, Nigeria.

(e-mail: ayabdullahi24@yahoo.com).

U. H. Goje, Nigerian Air Force, Nigeria.

(e-mail: gojeubaidu@ gmail.com).

A. Audu, Nigerian Air Force, Nigeria.

(e-mail: abdulmalikaudu ${ }^{\circledR}$ gmail.com).

I. N. Gana, Nigerian Air Force, Nigeria.

(e-mail: ganaisraelndamawo@gmail.com). 
metallic copper tube experienced a loss of signal strength due to eddy currents. However, it was suggested that this challenge could be addressed by using a more powerful transmitter when sending a signal to the RFID tag.

In a project carried out by Iyekoroghe et al. [7], a wireless handheld exploder using Short Wave (SW)-RF technology was designed. The major components used in the design include a transmitter, receiver, battery, antenna, and a SW generator which generates a $433 \mathrm{MHz}$ RF. The handheld exploder was designed to cover a range of $200 \mathrm{~m}$, however, only a range of $50 \mathrm{~m}$ was recorded during testing. The exploder also experiences some delay in signal transmission between the transmitter and receiver. The authors recommended the use of an external antenna as a means of increasing the range.

Salako et al. [8], designed and constructed a wireless exploder nicknamed SOE-12, employing the use of RF technology. The circuit consists of five main components: Direct Current (DC) power source, voltage regulator, microprocessor, transmitter module, receiver and a relay. The microcontroller was programmed using an Assembler programming language. The exploder was designed to cover a range of 100 metres for a maximum of $12 \mathrm{~kg}$ of explosive ordnances at a frequency of $433 \mathrm{MHz}$. However, a complete wireless system was not achieved due to the use of transmitter cable between the receiver and the trigger mechanism (detonator). Similarly, the exploder used an external power source which reduced its portability. In addition, the design calculations were not provided for future improvement and troubleshooting. Another major setback associated with the SOE-12 Exploder is that the Liquid Crystal Display (LCD) was used on the receiver instead of the transmitter [8].

A summary of the challenges associated with the reviewed literatures highlighted areas covering efficient power source, non-military applications, signal fluctuations, transmission range and portability issues. In view of these, this work attempts to build up on researches so far to overcome these challenges by designing a wireless exploder equipped with a long range antenna and efficient in-built power system employing RF technology. In addition to short range, portability and other shortcomings of the previous studies [78], the authors have not tested their exploders on explosives. They only achieved transmission between transmitters and receivers.

\section{MATERIALS AND METHODS}

The materials used for this work were sourced both locally and internationally as shown in Table I.

\section{A. Circuit Operation of Wireless Transmission}

In this work, the wireless exploder system is made up of 3 similar circuits for the 3 base stations, these base stations are: Transmitter (Tx) base station, Receiver ( $\mathrm{Rx}$ ) base station, and igniter circuits. Each base station is a connection of a microcomputer, a base module and the transceiver. Signal transmission is achieved by relaying signals from one base station to another using the principle of Voltage Controlled Oscillation (VCO).

$\mathrm{VCO}$ is a critical sub-block in communications transceivers used as frequency synthesizers. It is an oscillator with an output signal whose output can be varied over a range, which is controlled by the input DC voltage [9]. Alternation of the input voltage determines the oscillation rate. This oscillation occurs in variable state in the Resistor-Capacitive (RC) domain, where the frequency is proportional to the inverse of the square root of the RC network [10]. That is:

$$
f \propto \frac{1}{\sqrt{R C}}
$$

This frequency, $f$ is defined by:

$$
f(t)=f_{0}+k V_{c}(t)
$$

And,

$$
V_{c}=\frac{H^{2}}{V}
$$

where:

$V_{c}=$ Control Voltage.

$H^{2}=$ Harmonic Oscillation Squared,

$f=$ Real Oscillation Frequency,

$f_{0}=$ Nominal Oscillation Frequency,

$k=$ Tuning Gain,

For this project, the NRF24L01 transceiver is selected because of its wide range and noise suppressing ability. It is used in a half-duplex mode which allows signals to be transmitted in only one direction per time. This is because the communication between the transmitter and receiver is expected to flow in only one direction. The quality of the signal sent from the Tx transceiver depends on two key factors, low noise and antenna quality. Usually, the higher the signal frequency, the higher the noise. This is because if the noise problem is not handled, there will be almost zero output frequency. This challenge is addressed by the use of Low Noise Amplifier (LNA) at the input where the power is low. Therefore, the advantage of using a NRF24L01 transceiver module is that the noise will be suppressed by the use of filter capacitors and inductors. The Signal-to-Noise Ratio (SNR) within the Tx and Rx is given by [10]:

$$
F=\frac{S N R_{\text {in }}}{S N R_{\text {out }}}
$$

where:

$F$ - Noise Factor.

$S-$ Signal.

$N$ - Noise.

$R$ - Ratio

SNR is the ratio between the wanted signal and the unwanted background noise. It can be expressed in its most basic form using the SNR formula below [10]:

$$
S N R=\frac{P_{\text {signal }}}{P_{\text {noise }}}=\text { Signal to Noise Ratio; }
$$

where:

$P_{\text {signal }}$ - Power level of wanted signal (dB).

$P_{\text {noise }}-$ Power level of background noise (dB). 
TABLE I: SPECIFICATIONS OF THE COMPONENTS USED FOR THE FABRICATION OF THE YAMUGAG-20 EXPLODER

\begin{tabular}{|c|c|c|c|c|}
\hline $\mathrm{S} / \mathrm{N}$ & Components & Specification & Function & Picture \\
\hline 1. & LCD & Arduino $16 \times 4$ inch & To display commands & \\
\hline 2. & Relay Module & 1 Channel & $\begin{array}{l}\text { To control current flow in a } \\
\text { circuit }\end{array}$ & \\
\hline 3. & $\begin{array}{c}\text { Flexible } \\
\text { jumper wires }\end{array}$ & - & $\begin{array}{l}\text { For connecting two points on } \\
\text { a circuit without soldering }\end{array}$ & \\
\hline 4. & $\begin{array}{l}\text { Transceiver } \\
\text { module }\end{array}$ & NRF24L01 & $\begin{array}{c}\text { Responsible for placing } \\
\text { signals onto a network media } \\
\text { and also detecting incoming } \\
\text { signals }\end{array}$ & \\
\hline 5. & $\begin{array}{l}\text { Lithium } \\
\text { Battery }\end{array}$ & $3.7 \mathrm{~V}$ & $\begin{array}{l}\text { For generating current in the } \\
\text { igniter circuit }\end{array}$ & \\
\hline 6. & $\begin{array}{l}\text { Battery } \\
\text { Casing }\end{array}$ & $\begin{array}{l}\text { Lithium Battery } \\
\text { Casing }\end{array}$ & $\begin{array}{l}\text { For holding the battery in } \\
\text { position inside the exploder } \\
\text { casing }\end{array}$ & \\
\hline 7. & Batteries & $9 \mathrm{~V}$ & $\begin{array}{l}\text { Powers the microcontroller } \\
\text { circuits }\end{array}$ & \\
\hline 8. & Push Buttons & Red and Green & $\begin{array}{l}\text { Switch for powering the } \\
\text { device }\end{array}$ & \\
\hline 9. & Small Buzzer & - & $\begin{array}{l}\text { As audio signal device } \\
\text { during the arming of the } \\
\text { exploder }\end{array}$ & \\
\hline 10. & IC Socket & $4 \times 4$ & $\begin{array}{l}\text { Allows ICs to be inserted and } \\
\text { removed }\end{array}$ & \\
\hline 11. & $\begin{array}{l}\text { Variable } \\
\text { Resistor }\end{array}$ & $470 \mathrm{k}$ & $\begin{array}{l}\text { Allows more control over } \\
\text { current flow by changing the } \\
\text { amount of resistance }\end{array}$ & \\
\hline 12. & Resistors & $1 \mathrm{ohm}$ & $\begin{array}{l}\text { Control the flow of current to } \\
\text { other components in order } \\
\text { not to be damaged by too } \\
\text { much current. }\end{array}$ & \\
\hline 13. & $\begin{array}{l}\text { Pin Header } \\
\text { for Arduino }\end{array}$ & Male pins & $\begin{array}{l}\text { Used to connect Arduino } \\
\text { boards and shields together }\end{array}$ & \\
\hline 14. & $\begin{array}{l}\text { Vero board } \\
\text { lines }\end{array}$ & & $\begin{array}{l}\text { It is a general-purpose } \\
\text { material for constructing } \\
\text { electronic circuit. }\end{array}$ & \\
\hline
\end{tabular}

Also, the Noise Factor (NF) is given by [10]:

$$
N F=10 \log _{10}\left(\frac{S N R_{\text {in }}}{S N R_{\text {out }}}\right)=S N R_{\text {in.db }}-S N R_{\text {out } . d b}
$$

All parameter considerations and signal processing leading to transmission from $\mathrm{Tx}$ to $\mathrm{Rx}$ are within time domain. But working directly with respect to time gives so much challenge. To address this challenge, the principle of Fourier Transform is applied. This principle enables signal processing challenges to be converted from time-based to frequency-based and then back to time after solving. Equation 
(7) gives the signal equation in terms of time domain while equation (8) presents the equation in terms of frequency domain [11].

The Fourier transform of a signal $f$ is the function:

$$
F(\omega)=\int_{-\infty}^{+\infty} f e^{-j \omega t} d t
$$

$F$ is a function of a real variable $\omega$; the function value $F(\omega)$ is (in general) a complex number [11].

$|\mathrm{F}(\omega)|$ is called the amplitude spectrum of $f$.

Notation: $\mathrm{F}=\mathcal{F}(f)$ means $\mathrm{F}$ is the Fourier transform of $f$; similarly, in the frequency domain, we have:

The Fourier transform of a signal $g$ is the function

$$
F(t)=\frac{1}{2 \pi} \int_{-\infty}^{+\infty} g(w) e^{+j \omega t} d w
$$

$|F(t)|$ is called the amplitude spectrum of $t[11]$.

When all the conditions are met for the required output, the distance the signal can cover depends on the kind of antenna used. In this case, a rubber ducky antenna is used which gives a good multidirectional low noise transmission through long distances.

For relaying of signal, there is a Master Transmitter (MTx) base station, a Master Receiver-Slave Transmitter (MRxSTx) base station and a Slave Receiver (SRx) base station. The STx and SRx will be triggered by the MTx. This configuration is referred to as wireless serial communication.

The exploder system has arming and firing buttons. When the firing button is pressed while holding down the arming button, it triggers a signal chain reaction which is relayed from the MTx base station to the MRx-STx base station and finally to the SRx base station. The last receiver further relays the signal to an igniter circuit which generates the heat for the fuze to ignite. A computer program is written for coding the transmitters and receivers. The block diagram of the entire setup and the process of operation is given in Fig. 1.

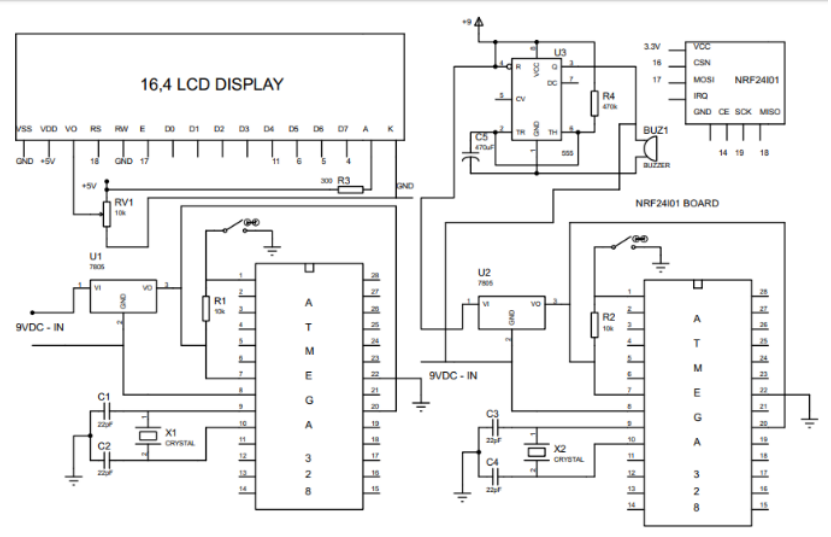

Fig. 1. Transmission Block Diagram for the Exploder Transmitter and Receiver system.

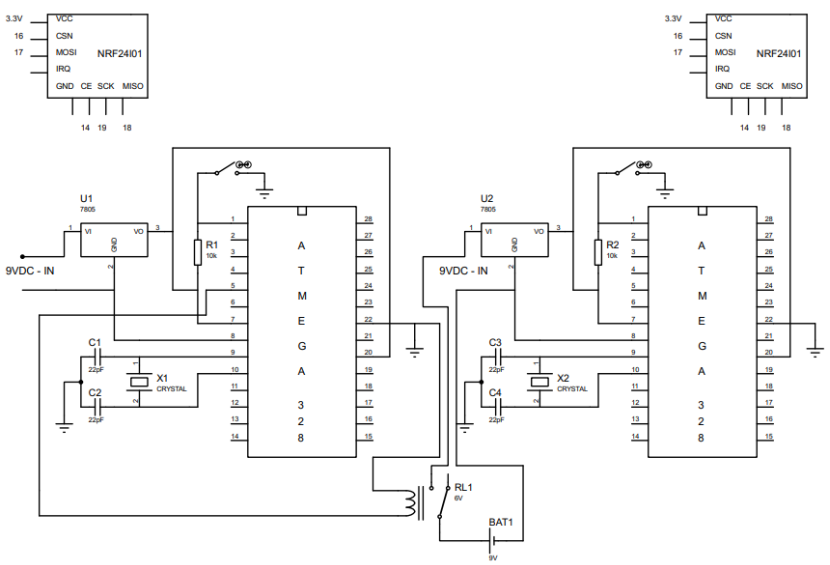

Fig. 2. Circuit Diagram of the Master Transmitter Unit.

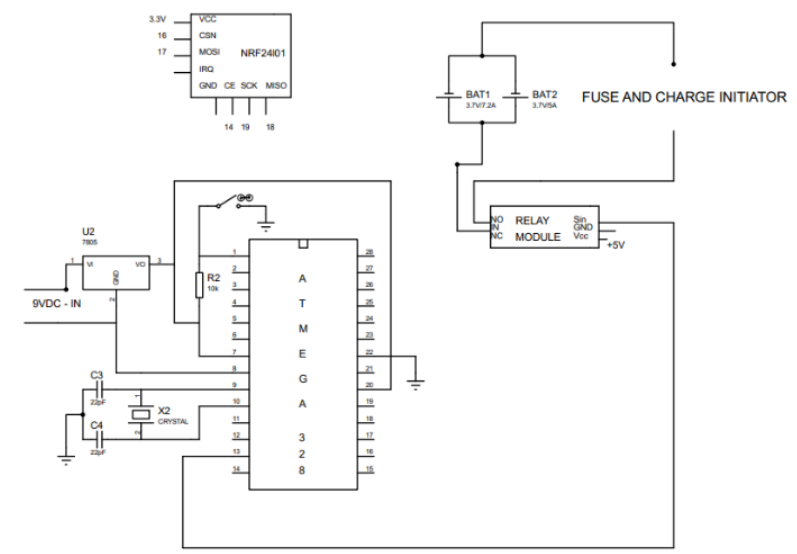

Fig. 3. Circuit Diagram of the Master Receiver-Slave Transmitter Unit

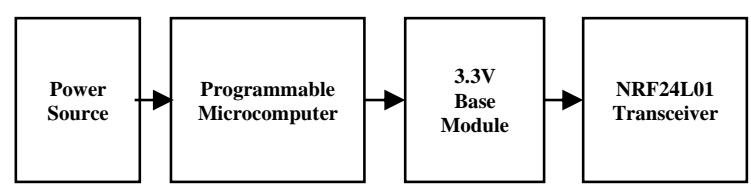

Fig. 4. Circuit Diagram of the Slave Receiver Unit.

\section{OPERATION OF YAMUGAG-20 WIRELESS EXPLODER SYSTEM}

The designed Exploder System is nicknamed YAMUGAG-20 Wireless Exploder System and comprises the following units:

i. The MTx Unit.

ii. The MRx - STx Unit.

iii.The SRx Unit.

These units work in a coordinated sequence to establish the wireless connection leading to the detonation of the USOs.

\section{A. Master Transmitter Unit}

This unit contains 3 main circuitries. The first circuit controls the display on the LCD. The second circuit regulates the delays needed for safe operation; these delays are programmed into the microcontroller and are adjustable at any time. An initial delay of 15 seconds is programmed upon pressing the "Arming Button" (Green Button) after powering on the transmitter. During this delay, there will be a warning sound from the buzzer to alert the operator and people around of what is about to happen. Meanwhile, the word 
"ARMING..." will be displayed on the LCD during this time. As soon as the warning sound from the buzzer ceases, the command "FIRE" will be displayed on the LCD. To achieve the detonation of the USOs, the "Fire Button" (Red Button) is pressed while still holding down the Arming Button. An additional 10-second delay was programmed before the detonation. The third circuit is a microcontroller responsible for relaying signals to the MRx-STx unit. The circuit diagram is shown in Fig. 2 and the picture of the complete assembly is shown in Fig. 5.

\section{B. Master Receiver-Slave Transmitter Unit}

The MRx-STx unit was introduced to increase the range of the exploder. It contains two Arduino microcontrollers. The first microcontroller is the MRx which receives signal from the MTx and relays it to the second microcontroller, the STx. This second microcontroller is responsible for further relaying the signal to the SRx unit. The circuit diagram and the picture of the complete assembly are shown in Fig. 3 and Fig. 6 respectively.

\section{Slave Receiver Unit}

This unit is the terminal stage where the signal received is processed and the explosion of the USOs is initiated. In addition to the microcontroller and transceiver module, the unit consists of a 12.2 Amps igniter power source $(2 \times 3.7 \mathrm{~V}$ batteries connected in parallel), a relay module, one-Ohm resistor, and a Fuze. Upon receiving the signal from the slave transmitter, a huge amount of current is generated by the igniter power source and passed through the resistor which generates the heat required to ignite the Fuze. The fire from the Fuze in turn detonates the USOs. The circuit diagram and the picture of the complete assembly are shown in Fig. 4 and Fig. 7 respectively.

\section{RESULTS AND DISCUSSION}

Pictures of the assembled components are shown below.

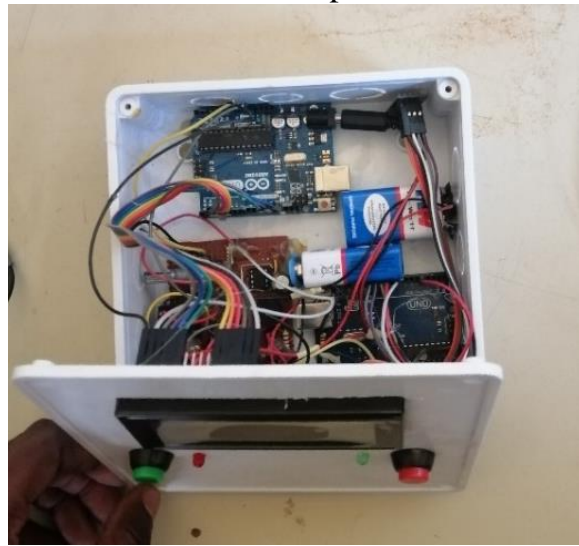

Fig. 5. MTx Unit.

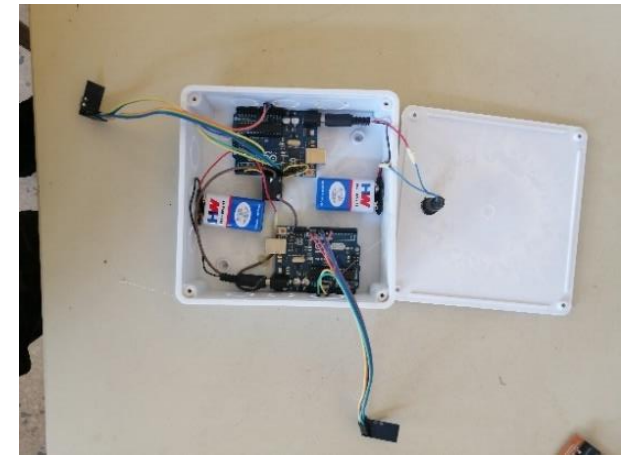

Fig. 6. MRx-STx Unit.

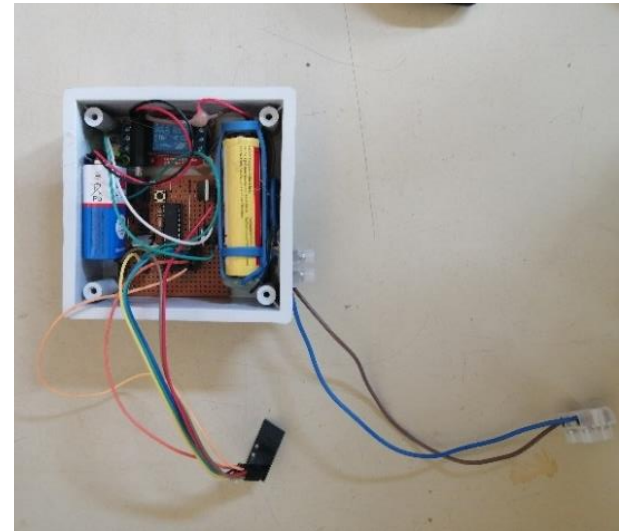

Fig. 7. SRx Unit.

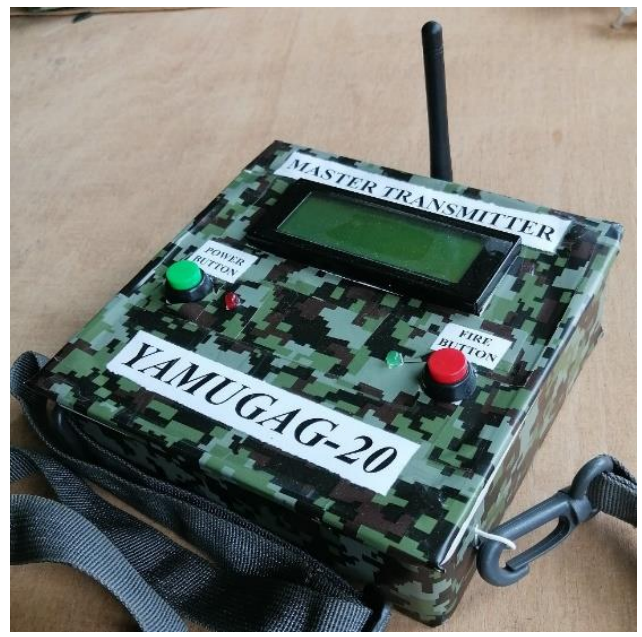

Fig. 8. Finished YAMUGAG-20 MTx Unit.

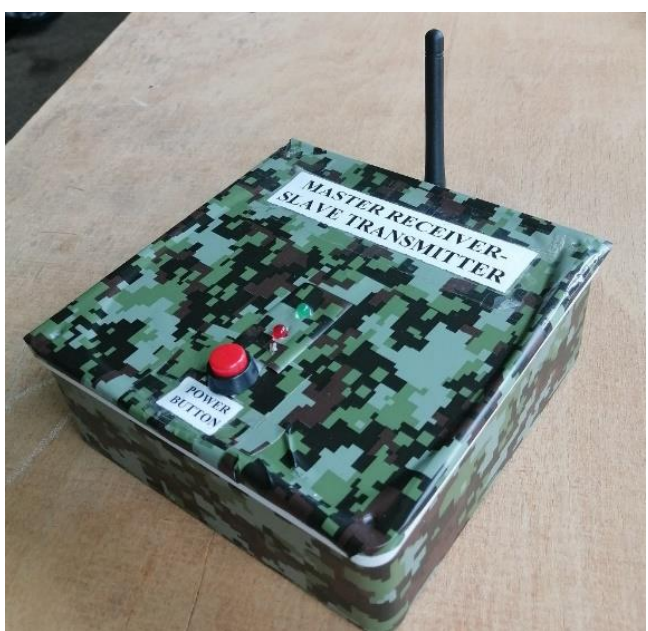

Fig. 9. Finished YAMUGAG-20 MRx-STx Unit. 


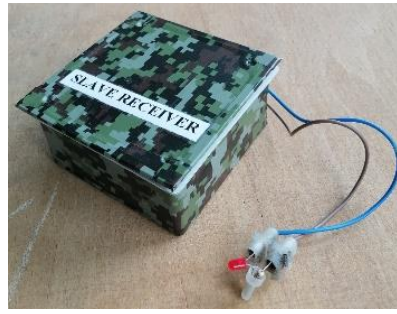

Fig. 10. Finished YAMUGAG-20 SRx Unit.

For RF designs deployed in the field, achievable RF range or wireless coverage is very important, which is impacted by many system design factors [15]. A simple and quick RF range test is used to determine the feasibility of an RF system and determine the RF link margin during application. Such a test can also be used to verify end-to-end RF performance for several critical system parameters as well as choosing critical external components such as an antenna or an external frontend module [15]. Key radio performance metrics are influenced by a harsh test environment.

Various measurements were carried out on the YAMUGAG-20 Wireless Exploder to establish the performance of the Exploder. It is important to note that the wireless exploder system transmits and receives signal at varying distances within the maximum range domain. The tests carried out include:

i. Functionality/Range Test.

ii. Power Consumption Test.

iii.System Reliability Test.

The results and analysis obtained from these tests are presented below. These tests were conducted on individual component basis and as a system using different test tools.

\section{A. Functionality/Range Test}

Functionality test was carried out to determine the proper operation of all components of the circuitry making up the Wireless Exploder System. While the range test helps in understanding how far the communication between the transmitter and receiver can be established. A transmission test carried out on the transmitters and receivers at different distances within the range recorded strong signals as shown in Table II. The signal strength of RF signals is measured using Wide Range RF Meter. However, due to the unavailability of the RF meter at the time of conducting this test, the signal strength was estimated based on the pre-set delay time of $15 \mathrm{sec}$. This was achieved by timing the duration of the complete communication, that is, the time the signal takes to travel from the moment the button was pressed to the time the USO explodes.

TABLE II: Signal StRENGTH of THE TRANSCEIVER AT DifFERENT RANGES

\begin{tabular}{ccccc}
\multicolumn{5}{c}{ RANGES } \\
\hline S/N & Distance $(\mathrm{m})$ & $\begin{array}{c}\text { Time } \\
(\mathrm{secs})\end{array}$ & Signal Strength & Remarks \\
\hline 1. & 200 & 15.0 & Excellent & - \\
2. & 400 & 15.0 & Excellent & - \\
3. & 600 & 15.0 & Excellent & - \\
4. & 800 & 15.0 & Excellent & - \\
5. & 1000 & 15.5 & Excellent & - \\
6. & 1050 & 16.0 & Strong & - \\
7. & 1100 & 17.0 & Weak & - \\
8. & 1150 & - & No signal & $\begin{array}{c}\text { Beyond the } \\
\text { designed range } \\
\text { of transceiver }\end{array}$ \\
\hline
\end{tabular}

Furthermore, the explosives used for the test detonation include ammonium nitrate, gun powder, electric detonator, and a combination of plastic explosive with an electric detonator and they all detonated successfully.

\section{B. Power Consumption Test}

The power consumption test was conducted on powersensitive components such as the Arduino modules, relay switches and relay module as well as the NRF24L01 transceiver. The results showed that there was power depletion after a few test runs of the Exploder. The voltage of the battery measured using a multimeter after 3 test runs was observed to drop from $9 \mathrm{~V}$ to $8.1 \mathrm{~V}$ which indicates about $10 \%$ voltage drop.

\section{System Reliability Test}

System reliability test measures the endurance and ruggedness of the equipment when subjected to both favourable and harsh environments. The ability of the equipment to function optimally under all conditions increases its flexibility, durability and the eventual market value of the equipment. The Exploder was tested under the prevailing atmospheric condition of wind, temperature and humidity at different locations around the place of production and the performance was satisfactory.

However, additional tests in other locations with different weather conditions will be needed in order to obtain a comprehensive performance evaluation of the Exploder system.

\section{COST ANALYSIS}

A cursory analysis of the prices of commercial wireless exploders commonly referred to as remote firing systems showed prices of such devices ranging between 800USD to about 10,000USD per unit [12]. But these are the selling prices and not the exact cost of production of the entire system.

One of the methods used by companies to maximize their profits is called cost-based pricing. Cost-based pricing involves calculating the cost of the product plus a percentage mark-up to determine the price. Mark-up is the difference between the cost of a good or service and its selling price. It is added on the total cost incurred by the producer of a good or service in order to create a profit [13].

Therefore, for the YAMUGAG-20 Exploder, the cost incurred for the production was $\$ 188,890$ equivalent to 489.85USD for one USD to 385.61 Naira conversion rate as at 15 September 2020 [14]. Assuming a mark-up price of $10 \%$ production cost, which is equivalent to N18,889 (48.99 USD), the selling price for the YAMUGAG-20 Exploder is expected to be 538.84 USD ( $\$ 207,782.09$ ) which is relatively cheaper compared to the cheapest available commercial wireless exploders. Although the YAMUGAG-20 Exploder is not yet due for commercialization, but preliminary analysis has shown that it has the potential of being cheaper than other commercial wireless exploders in the market. 


\section{CONCLUSION}

In this paper, a Radio Frequency-based Wireless Exploder nicknamed YAMUGAG-20 capable of covering a range of $1000 \mathrm{~m}$ was designed using the principle of Voltage Controlled Oscillation (VCO). The construction was achieved by connecting a microcomputer, base module and a transceiver. The Exploder comprises the MTx Unit, MRx/STx Unit, and the SRx Unit. These units work sequentially to establish the wireless connection leading to the detonation of the USOs.

Various measurements were carried out to establish the performance of the Exploder and also to determine the feasibility of the RF system to verify end-to-end RF performance for several critical system parameters. The parameters tested include: functionality test, range test, power consumption test, and system reliability test. Results obtained from the tests indicated that the Exploder performed satisfactorily and has the potential of both military and civil applications in the nearest future subject to further testing and improvement.

\section{ACKNOWLEDGMENT}

We acknowledge the support and contribution of Armament Engineering Department (ARMED) and the Air Force Institute of Technology (AFIT), Nigerian Air Force (NAF), for providing the enabling environment, resources and intellectual guidance during the course of this work.

\section{REFERENCES}

[1] Ezekiel, D. A. (2020, June 5). Challenges of Using Wired Exploders in Demolition at 633 CAD. (A. Y. Abdullahi, \& I. N. Gana, Interviewers).

[2] Zuraida, A. B., Fairuz, S. D., Risby, M. S., Amirah, A., \& Raziff, A. R. (2017). An Investigation on Detonator Triggering Effect Subjected to Radio Frequency Energy Exposure. Journal of Fundamental and Applied Sciences, 28-40.

[3] Dirk, H., McCann, M. J., \& Stewart, R. F. (2009). United States of America Patent No. 076777.

[4] N.C. Department of Labor Occupational Safety and Health Division. (2009). A Guide to Radio Frequency Hazards with Electric Detonators Washington: N.C. Department of Labor Occupational Safety and Health Division.

[5] Cochrane, B. (2014). Exploders. The Journal of the Institute of Explosives Engineers, 34-35.

[6] Koekemoer, A., Schlenter, C. C., Julien Louis, D. A., \& Maurissens. (2014). United States of America Patent No. 0311370 A1.

[7] Iyekoroghe, S. E., Saka, H. O., Maxwell, B., \& Abonyi, I. N. (2017). Construction of Handheld Exploder. Kaduna: Armament Engineering Department (ARMED), Air Force Institute of Technology (AFIT).

[8] Salako, A. I., Olawale, A. O., \& Ekede, O. O. (2019). The Design and Construction of SOE-12 Wireless Exploder. Kaduna: Armament Engineering Department (ARMED), Air Force Institute of Technology (AFIT).

[9] ELPROCUS. (2020, May 25). Retrieved from ELPROCUS Web site: https://www.elprocus.com.

[10] Electronic Tutorials. (2020, May 24). Retrieved from Electronic Tutorials Websites: https://www.electronics-tutorials.ws.

[11] Stanford University. (2020, July 26). Stanford University. Retrieved from Stanford University Web site: http://www.stanford.edu.

[12] Blasters Tool \& Supply Co. (2020, September 15). Blasters Tool \& Supply Co. Retrieved from Blasters Tool \& Supply Co. Web site: http://www.blasterstool.com.

[13] Lumen Boundless Business. (2020, September 15). Product and Pricing Strategies: Pricing Methods. Retrieved from Lumen Boundless Business Web site: http://courses.lumenlearning.com.

[14] Google Finance. (2020, September 15). Google Finance. Retrieved from Google Finance Web site: http://www.google.com.
[15] NXP Semiconductors. (2017, February 23). How to Achieve Optimal RF Range on a Wireless System Using KW41. 